\title{
CYP1A1 MspI Polymorphism and Cervical Carcinoma Risk in the Multi-Ethnic Population of Malaysia: a Case-Control Study
}

\author{
Yee Hock Tan ${ }^{1}$, Shiran Mohd Sidik ${ }^{2}$, Sharifah Noor Akmal Syed Husain ${ }^{3}$, Munn \\ Sann Lye ${ }^{4}$, Pei Pei Chong ${ }^{1 *}$
}

\begin{abstract}
Background: Tobacco smoking is considered a risk factor for cervical cancer development due to the presence of tobacco based carcinogenic metabolites in cervical cells of female smokers. In this study, we investigated the role of the T3801C (MspI) polymorphism of CYP1A1, a gene encoding an enzyme necessary for the initiation of tobacco based carcinogen metabolism, on cervical cancer risk. The $\mathrm{T}$ to $\mathrm{C}$ substitution may alter $\mathrm{CYP1A1}$ activities, potentially elevating cervical cancer risk. Since results of gene-disease association studies vary according to the study population, the multi-ethnic population of Malaysia provides an excellent representative cohort for identifying and comparing the cervical cancer risk among the 3 major ethnics in Southeast Asia in relation to CYP1A1 MspI polymorphism. Materials and Methods: A total of 195 Thin Prep Pap smear samples from HPV negative and cancer free females were randomly selected as controls while 106 formalin fixed paraffin embedded samples from females with invasive cervical cancer were randomly selected for the cases group. The polymorphisms were identified using restriction fragment length polymorphism (RFLP) PCR. Results: We found no significant associations between CYP1A1 MspI polymorphism and cervical cancer in the general Malaysian female population. However, upon ethnic stratification, the variant $\mathrm{C} / \mathrm{C}$ genotype was significantly associated with a 4.66-fold increase in cervical cancer risk in Malay females $(95 \% \mathrm{CI}=1.21-17.9 ; \mathrm{p}=0.03)$. No significant association was observed in the Chinese and Indian females. Additionally, there were no significant associations in the dominant model and allele frequency model analysis in both the general and ethnically stratified female population of Malaysia. Conclusions: Our findings suggest that the C/C genotype of CYP1A1 MspI polymorphism is associated with the development of cervical carcinoma in the Malay females of Malaysia.
\end{abstract}

Keywords: CYP1A1 - MspI - cervical cancer - SNP - Malaysia

Asian Pac J Cancer Prev, 17 (1), 57-64

\section{Introduction}

Cervical carcinoma is one of the most prominent malignancies found in females worldwide. In 2002 alone, an estimated total of at least 500,000 cases and 275,000 deaths are attributed to the carcinoma globally (Parkin et al., 2005). The lack of accessible Pap smear screening, HPV vaccination, and health education leads to a higher prevalence of cervical carcinoma in developing countries, which represents a staggering $80 \%$ of the total cervical carcinoma cases worldwide (Schiffman et al., 2007; Hoory et al., 2008).

In Malaysia, a multi-ethnic developing nation in South East Asia, around 850 cases of cervical carcinoma had been reported in 2007 , making up $8.4 \%$ of the total cancer incidence reported that year. The estimation puts cervical carcinoma as the third most common female malignancy in Malaysia, behind breast and colorectal carcinoma. The malignancy is most common in the Indians, followed by the Chinese and the Malay ethnics with an age standardized rate (ASR) of 10.3,9.5 and 5.3 respectively (Zainal Ariffin and Nor Saleha, 2011).

Persistent infection with high risk human papillomavirus has long been a pre-criterion to cervical carcinogenesis (Remmink et al., 1995; Schiffman et al., 2007). HPV-16 and HPV-52 have been commonly found in the abnormal smears, cervical intraepithelial lesions as well as invasive cancers of Malaysian females (Sharifah et al., 2009), although as high as $47 \%$ of the cervical cancer-free, healthy population has been found to harbour HPV-16 and other HPV types including HPV-18, HPV33, and HPV-31, all capable of inducing carcinogenesis (Chong et al., 2010). Subsequently, another similar HPV genotype study found that HPV-16, HPV-18, HPV-58, HPV-33 and HPV-52 are among the most prevalent high risk HPV genotypes in Malaysia (Hamzi Abdul Raub et

${ }^{1}$ Department of Biomedical Science, ${ }^{4}$ Department of Community Health, Faculty of Medicine and Health Sciences, Universiti Putra Malaysia, ${ }^{2}$ Department of Pathology, Perdana University, Selangor, ${ }^{3}$ Department of Pathology, Faculty of Medicine, Universiti Kebangsaan Malaysia, Kuala Lumpur, Malaysia*For correspondence: cpp@upm.edu.my 
al., 2014). This is not surprising as HPV-16 and HPV-18 have been reported to be responsible for almost $70 \%$ of cervical carcinoma cases worldwide (Smith et al., 2007). These high risk HPVs may attribute to the high incidence of cases reported in Malaysia.

Interestingly, HPV infection does not indicate absolute certainty of progression to malignancy since only less than $1 \%$ of HPV infection leads to invasive cancer (Barbisan et al., 2011). Therefore HPV infection alone may not be sufficient for carcinogenesis and there are other possible contributing risk factors. One of these risk factors is smoking (Goodman et al., 2001). Exposure to cigarette or tobacco smoking, as well as passive smoke is linked to accumulation of harmful carcinogens at the cervix (McCann et al., 1992; Prokopczyk et al., 1997). These carcinogens are normally broken down by the biological activation of the CYPIAl genes and later detoxified by the enzymes encoded by the GST family genes (Sreelekha et al., 2001). If any of the metabolizing or detoxifying enzymes are non-functional, these carcinogens could accumulate, causing damage to the cervical cells (Bartsch et al., 1992; Bonassi and Au, 2002; Au et al., 2003). This coupled with the inactivation of critical apoptosis and cell cycle regulation components by high risk HPV could favour carcinogenesis of the cervical cells over regression of the HPV infection.

CYP1Al is a critical member of the cytochrome P450 family of enzymes (Smith et al., 1998). The gene encodes an enzyme which breaks down the carcinogens into manageable epoxide intermediates which are detoxified by the glutathione S-transferase family of enzymes (Sreelekha et al., 2001). Biotransformation of this gene leads to an increase of reactive intermediates which are harmful should the level of detoxification remained constant (Autrup, 2000). A single nucleotide polymorphism (SNP) of CYP1A1 at position 3801 in the 3 ' untranslated region results in a change of a $\mathrm{T}$ to $\mathrm{C}$ base (Spurr et al., 1987). Consequently, this resulting MspI polymorphism has been extensively studied alongside numerous malignancies including cervical carcinoma, esophageal carcinoma, oral carcinoma, breast carcinoma, colorectal cancer and lung carcinoma (Sivaraman et al., 1994; Tanimoto et al., 1999; Kim et al., 2000; Goodman et al., 2001; Boyapati et al., 2005; Joseph et al., 2006; Agorastos et al., 2007; Juarez-Cedillo et al., 2007; Nishino et al., 2008; Gutman et al., 2009; Chen et al., 2011; von Keyserling et al., 2011; Sergentanis et al., 2012; Shukla et al., 2012; Zhuo et al., 2012a; Zhuo et al., 2012b; Ding et al., 2013; Islam et al., 2013; Liu et al., 2013; Saeed et al., 2013; Shukla et al., 2013; Xia et al., 2013; Yun et al., 2013; Jiang et al., 2014). The association between this CYP1Al polymorphism with cervical carcinoma has been examined previously in various populations, with mixed results. However, it has not been studied in the Malaysian population.

In this study, we examined the CYPlAl MspI SNP (rs4646903) in 301 females from the Selangor region of Malaysia. The subjects, females from the three main ethnics of Malaysia, were segregated into two main groups consisting of cases and controls. Cases included patients with invasive cancer, either with squamous-cell carcinoma
(SCC), adenocarcinoma (ADC) or adenosquamous carcinoma (ADSC) while controls consisted of women who were cancer free and tested negative for HPV.

\section{Materials and Methods}

\section{Study subjects}

This is a case-control study of 195 control subjects and 106 cervical cancer patients. For the control population, samples were randomly selected from a bank of Thin Prep samples collected for Pap smear screening at Hospital Universiti Kebangsaan Malaysia (HUKM), Malaysia. These samples were designated as normal controls as no apparent lesions were detected through the cytology screening and no HPV was detected through PCR. For the cases, we recruited 106 patients with diagnosed cervical cancer who had their tissues collected and archived throughout the period from 2006 to 2008 at the same hospital, again through random selection process. The formalin fixed paraffin embedded (FFPE) tissues were categorized into SCC, ADC and ADSC type carcinoma (Table 1) following the International Federation of Gynecology and Obstetrics (FIGO) guidelines. Ethics approval for usage of the samples in research was granted by the Medical Research and Ethnics Committee of Universiti Kebangsaan Malaysia, UKM under the project code FF-180-2008. No consent was obtained because aside from the age, ethnicity and cancer type of the study subjects, patients' information were de-identified and has been made anonymous prior to analysis. DNA was extracted from the samples using QiaAmp DNA Mini Kit (Qiagen GmbH, Germany).

\section{Determination of CYP1A1 polymorphism}

The single nucleotide polymorphism of the samples extracted was determined using restriction fragment length polymorphism (RFLP). The DNA was first amplified using the following primers: CYP-F (forward): 5'- GAG GAA GAA GAG GAG GTA GCA G-3'; and CYP-R (reverse): 5' - TGA GGT GGG AGA ATC GTG TGA-3'.

The primers were modified from a previous study (Sivaraman et al., 1994), generating shorter amplicons in order to improve the efficiency of primer binding to our archival FFPE tissue samples.

The PCR for each sample was carried out in duplicates of $50 \mu \mathrm{l}$ each containing 0.20 to $0.50 \mu \mathrm{g}$ of genomic DNA, $0.20 \mu \mathrm{M}$ of both forward and reverse primers, $0.20 \mathrm{mM}$

Table 1. Characteristics of the study population

\begin{tabular}{lrrr}
\hline & Control & Cases & Total \\
\hline Mean age & 40.8 & 52.6 & 45 \\
(Range) & $(21-73)$ & $(24-84)$ & $(21-84)$ \\
Ethnicity & & & \\
Malay & 65 & 54 & 119 \\
Chinese & 89 & 34 & 123 \\
Indian & 41 & 18 & 59 \\
Carcinoma type & & & \\
NILM & 195 & & \\
Squamous cell carcinoma (SCC) & & 37 & \\
Adenocarcinoma (ADC) & & 66 & \\
Adenosquamous carcinoma (ADSC) & 3 & \\
\hline
\end{tabular}


of each of the four deoxynucleotide phosphates, $1.25 \mathrm{U}$ of EURx Taq polymerase (EURx, Poland) and 1x PCR buffer. The amplification was carried out using BIORAD C1000 Thermal Cycler with an initial denaturation temperature of $94^{\circ} \mathrm{C}$ for 5 minutes followed by 35 cycles of $94^{\circ} \mathrm{C}$ for 30 seconds, $55^{\circ} \mathrm{C}$ for 30 seconds and $72^{\circ} \mathrm{C}$ for 45 seconds with a final extension step of $72^{\circ} \mathrm{C}$ for 5 minutes. The PCR products were then analysed with gel electrophoresis using a $1.5 \%$ agarose gel stained with ethidium bromide on a UV transilluminator. The primers amplify a 179bp region containing the MspI polymorphic site.

\section{Purification of CYPIAl PCR products and RFLP}

Each sample was amplified in duplicates of 2 separate microtubes and upon confirmation of amplification through electrophoresis; the amplicons from the two reactions were pooled and purified using Thermo Scientific GeneJET PCR purification kit (Thermo Fisher Scientific Inc, USA). The purified PCR products (50 ng) were digested using FastDigest MspI restriction enzyme (Thermo Fisher Scientific Inc, USA). The resulting amplicons were analysed with gel electrophoresis using a 3\% gel stained with ethidium bromide on a UV transilluminator. The MspI digestion produces a 24bp and $155 \mathrm{bp}$ band or a 24bp, $155 \mathrm{bp}$ and $179 \mathrm{bp}$ band for the homozygous $\mathrm{C} / \mathrm{C}$ variant and heterozygous $\mathrm{T} / \mathrm{C}$ variant respectively while the wild type T/T remained undigested leaving a sole $179 \mathrm{bp}$ band after gel electrophoresis (Figure 1). For verification, $15 \%$ of the RFLP results were confirmed via sequencing of the PCR products ( $1^{\text {st }}$ Base Laboratories). CYP1A1 MspI SNP

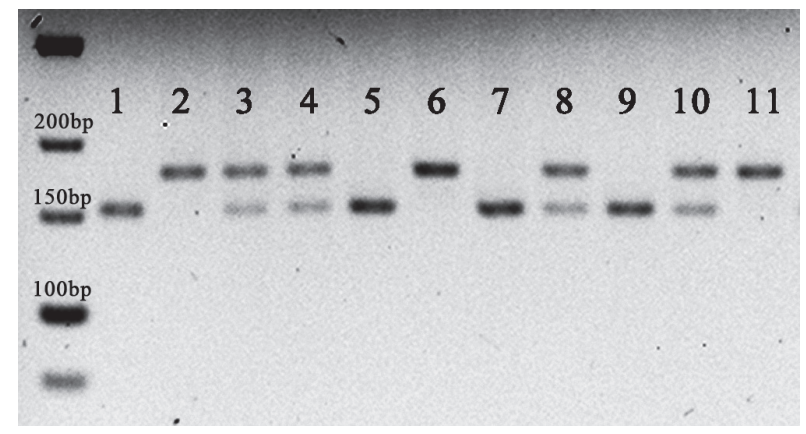

Figure 1. Electrophoresis of amplicons after MspI Restriction Enzyme Digestion. Lanes 2,6,11 shows undigested $179 \mathrm{bp}$ band where the restriction enzyme site was not present and indicating the samples are wild type homozygous $\mathrm{T} / \mathrm{T}$. Lanes $3,4,8,10$ show the $179 \mathrm{bp}$ and $155 \mathrm{bp}$ bands indicating that the samples are heterozygous T/C. Lanes 1,5,7,9 show full digestion of the original PCR amplicon resulting in only the $155 \mathrm{bp}$ band indicating that the samples are the homozygous $\mathrm{C} / \mathrm{C}$ variant. The $24 \mathrm{bp}$ band was not visible in the gel due to its small size and hence was not used in determining the SNP genotypes. No deviation was found between the RFLP results and the sequencing data.

\section{Data analysis}

Statistical analysis of the data was done using the Statistical Package for Social Sciences (SPSS) software. The association between $C Y P 1 A 1$ allele frequencies with cervical cancer risk was analysed by calculating the odds ratio $(\mathrm{OR})$ and $95 \%$ confidence intervals $(95 \% \mathrm{CI})$ using the $X^{2}$ test. The adjusted odds ratios for independent variables were determined using unconditional logistic regression analysis with the wild type genotype $\mathrm{T} / \mathrm{T}$ as the referent category. The odds ratios were adjusted mainly according to age and ethnicity. Since smoking and other socioeconomic status of the study population were not known, control of those potential confounders was not able to be carried out. The $\mathrm{P}$ values reported in the study are based on two sided probability test with a significance level of $\mathrm{p}<0.05$.

\section{Results}

A total of 106 females with cervical carcinoma and 195 female controls were examined. The mean age, ethnicity and type of invasive cancer of the study population is
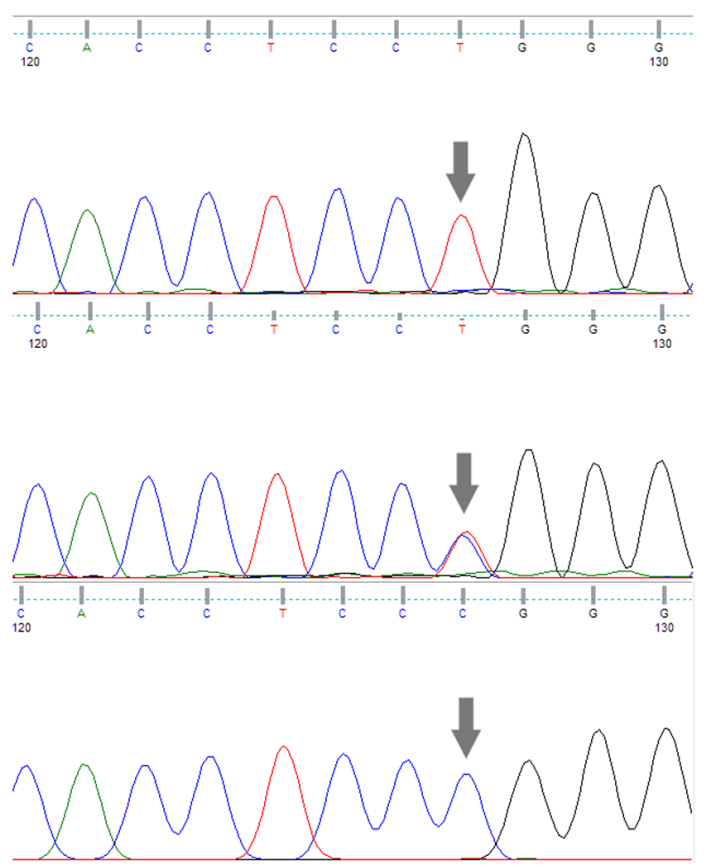

Figure 2. MspI Sequencing Chromatogram. The arrow points at the MspI SNP site. (a) shows the base at the SNP as a $\mathrm{T}$ (wild type homozygous). (b) shows the base to be either a $\mathrm{T}$ or a $\mathrm{C}$ (heterozygous $\mathrm{T} / \mathrm{C}$ ) while (c) shows the base to be a $\mathrm{C}$ (homozygous variant)

Table 2. Odds Ratios and 95\% CI of Invasive Cervical Carcinoma Associated with CYP1A1 Genotypes

\begin{tabular}{lcclcc}
\hline Genotype $(\mathrm{n} ; \%)$ & Controls, $\mathrm{n}(\%)$ & Cases, $\mathrm{n}(\%)$ & OR $^{\mathrm{b}}$ & $95 \%$ CI & $\mathrm{p}$ \\
\hline Total $(301)$ & & & & & \\
T/T $(113 ; 37.5 \%)$ & $78(40.0 \%)$ & $35(33.0 \%)$ & $1^{\mathrm{a}}$ & - & - \\
T/C $(134 ; 44.5 \%)$ & $87(44.6 \%)$ & $47(44.3 \%)$ & 1.52 & $0.81-2.86$ & 0.20 \\
C/C $(54 ; 17.9 \%)$ & $30(15.4 \%)$ & $24(22.6 \%)$ & 2.16 & $0.95-4.89$ & 0.07 \\
T/C+C/C vs T/T & & & 1.68 & $0.93-3.03$ & 0.09 \\
\hline
\end{tabular}

a Reference category; ${ }^{\text {} O d d s ~ r a t i o ~ a r e ~ b a s e d ~ o n ~ a n ~ u n c o n d i t i o n a l ~ l o g i s t i c ~ r e g r e s s i o n ~ m o d e l ~ w i t h ~ t h e ~ i n d e p e n d e n t ~ v a r i a b l e: ~ t y p e s ~ o f ~ g e n o t y p e ~(w i l d ~}$ type, heterozygous, homozygous variant SNP), adjusted for age and ethnicity 
Table 3. Odds ratios and $95 \%$ CI of Invasive Cervical Carcinoma associated with CYP1A1 Genotypes stratified according to ethnicity

\begin{tabular}{|c|c|c|c|c|c|}
\hline Genotype (n; \%) & Controls, n (\%) & Cases, n (\%) & $\mathrm{OR}^{\mathrm{b}}$ & $95 \% \mathrm{CI}$ & $\mathrm{p}$ \\
\hline \multicolumn{6}{|l|}{ Malay (119) } \\
\hline $\mathrm{T} / \mathrm{T}(42 ; 35.3 \%)$ & $25(38.5 \%)$ & $17(31.5 \%)$ & $1^{\mathrm{a}}$ & - & - \\
\hline $\mathrm{T} / \mathrm{C}(54 ; 45.4 \%)$ & $32(49.2 \%)$ & $22(40.7 \%)$ & 1.75 & $0.61-5.03$ & 0.30 \\
\hline $\mathrm{C} / \mathrm{C}(23 ; 19.3 \%)$ & $8(12.3 \%)$ & $15(27.8 \%)$ & 4.66 & $1.21-17.9$ & $0.03^{*}$ \\
\hline $\mathrm{T} / \mathrm{C}+\mathrm{C} / \mathrm{C}$ vs $\mathrm{T} / \mathrm{T}$ & & & 2.40 & $0.90-6.39$ & 0.08 \\
\hline \multicolumn{6}{|l|}{ Chinese (123) } \\
\hline $\mathrm{T} / \mathrm{T}(49 ; 39.8 \%)$ & $38(42.7 \%)$ & $11(32.4 \%)$ & $1^{\mathrm{a}}$ & - & - \\
\hline $\mathrm{T} / \mathrm{C}(54 ; 43.9 \%)$ & $39(43.8 \%)$ & $15(44.1 \%)$ & 1.50 & $0.54-4.13$ & 0.44 \\
\hline $\mathrm{C} / \mathrm{C}(20 ; 16.3 \%)$ & $12(13.5 \%)$ & $8(23.5 \%)$ & 3.91 & $0.95-16.1$ & 0.06 \\
\hline $\mathrm{T} / \mathrm{C}+\mathrm{C} / \mathrm{C}$ vs $\mathrm{T} / \mathrm{T}$ & & & 1.86 & $0.72-4.84$ & 0.20 \\
\hline \multicolumn{6}{|l|}{ Indian (59) } \\
\hline $\mathrm{T} / \mathrm{T}(22 ; 37.3 \%)$ & $15(36.6 \%)$ & $7(38.9 \%)$ & $1^{\mathrm{a}}$ & - & - \\
\hline $\mathrm{T} / \mathrm{C}(26 ; 44.1 \%)$ & $16(39.0 \%)$ & $10(55.6 \%)$ & 1.40 & $0.38-5.20$ & 0.62 \\
\hline $\mathrm{C} / \mathrm{C}(11 ; 18.6 \%)$ & $10(24.4 \%)$ & $1(5.6 \%)$ & 0.13 & $0.01-1.63$ & 0.11 \\
\hline $\mathrm{T} / \mathrm{C}+\mathrm{C} / \mathrm{C}$ vs $\mathrm{T} / \mathrm{T}$ & & & 0.84 & $0.25-2.86$ & 0.78 \\
\hline
\end{tabular}

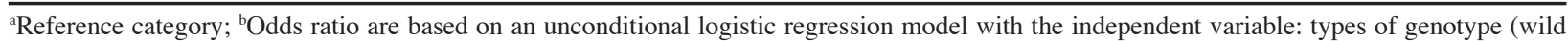
type, heterozygous, homozygous variant SNP), adjusted for age and ethnicity

Table 4. Allele Frequencies and Odds Ratio of CYP1A1 T/C Polymorphism among Women with Cervical Carcinoma and Controls

\begin{tabular}{|c|c|c|c|c|c|}
\hline Allele $(\%)$ & Control & Cases & P value ${ }^{a}$ & Chi-Square Value & $\begin{array}{l}\text { Odds Ratiob }^{\mathrm{b}} \\
(95 \% \mathrm{CI})\end{array}$ \\
\hline \multicolumn{6}{|l|}{ Malay } \\
\hline $\mathrm{T}(58.0 \%)$ & $82(63.1 \%)$ & $56(51.9 \%)$ & 0.11 & 2.61 & $1.59(0.94-2.67)$ \\
\hline $\mathrm{C}(42.0 \%)$ & $48(36.9 \%)$ & $52(48.1 \%)$ & & & \\
\hline \multicolumn{6}{|l|}{ Chinese } \\
\hline $\mathrm{T}(61.8 \%)$ & $115(64.6 \%)$ & $37(54.4 \%)$ & 0.19 & 1.76 & $1.53(0.87-2.70)$ \\
\hline $\mathrm{C}(38.2 \%)$ & $63(35.4 \%)$ & $31(45.6 \%)$ & & & \\
\hline \multicolumn{6}{|l|}{ Indian } \\
\hline $\mathrm{T}(59.3 \%)$ & $46(56.1 \%)$ & $24(66.7 \%)$ & 0.38 & 0.76 & $0.64(0.28-1.45)$ \\
\hline $\mathrm{C}(40.7 \%)$ & $36(43.9 \%)$ & $12(33.3 \%)$ & & & \\
\hline \multicolumn{6}{|l|}{ Total } \\
\hline $\mathrm{T}(59.8 \%)$ & $243(62.3 \%)$ & $117(55.2 \%)$ & 0.11 & 2.61 & $1.34(0.96-1.89)$ \\
\hline $\mathrm{C}(40.2 \%)$ & $147(37.7 \%)$ & $95(44.8 \%)$ & & & \\
\hline
\end{tabular}

${ }^{\mathrm{a} A l l} \mathrm{p}$-values are two tailed and adjusted for Yates Correction for Continuity. A p-value of $<0.05$ is consider statistically significant; ${ }^{\text {b }} \mathrm{Crude}$ odds ratio

shown in Table 1. Among the cervical carcinoma patients, 37 had SCC, 66 had ADC whereas only 3 had ADSC. The mean age of the patients was 52.6 (range, 24-84) while the control subjects' mean age was 40.8 (range, 21-73). The distribution of ethnicity of the controls was $65(33.3 \%)$ Malay, 89 (45.6\%) Chinese and 41 (21\%) Indian. The distribution of the cases on the other hand more or less reflected the national population distribution with 54 (50.9\%) Malay, 34 (32.1\%) Chinese and 18 (17\%) Indian.

Table 2 shows the CYP1Al genotype frequencies of females with cervical carcinoma compared to non-cancer controls. The distribution of the CYPIAl genotypes in our population was in Hardy-Weinberg equilibrium. In the general study population, we observed an increase in the frequency of variant $\mathrm{C} / \mathrm{C}$ genotype among females with cervical cancer $(22.6 \%)$ compared to controls $(15.4 \%)$. However, this increase in variant $\mathrm{C} / \mathrm{C}$ genotype in cervical cancer cases was non-significant in the general study population $(\mathrm{OR}=2.16 ; 95 \% \mathrm{CI}=0.95-4.89 ; \mathrm{p}=0.07)$. No significant difference was found between the heterozygous genotype $\mathrm{T} / \mathrm{C}$ and the wild type $\mathrm{T} / \mathrm{T}$ in relation to the risk of cervical cancer $(\mathrm{OR}=1.52 ; 95 \% \mathrm{CI}=0.81-2.86$; $\mathrm{p}=0.20$ ). Aside from that, no significant difference was found when a dominant model analysis was carried out using $\mathrm{C}$ allele as the high risk allele $(\mathrm{OR}=1.68 ; 95 \% \mathrm{CI}=$ 0.93-3.03; $\mathrm{p}=0.09$ ).

Table 3 shows the odds ratio and $95 \% \mathrm{CI}$ after ethnicity stratification. The homozygous variant $\mathrm{C} / \mathrm{C}$, when compared to wild type $\mathrm{T} / \mathrm{T}$, is significantly associated with a 4.66 increase in risk of cervical carcinoma among Malay females $(95 \% \mathrm{CI}=1.21-17.9 ; \mathrm{p}=0.03)$. Similarly, an increase in risk was observed within Chinese females for variant $\mathrm{C} / \mathrm{C}$. However, the increased risk was found to be statistically quite close to the significant level $(\mathrm{OR}=3.91 ; 95 \% \mathrm{CI}=0.95-16.1 ; \mathrm{p}=0.06)$. Comparison between heterozygous $\mathrm{T} / \mathrm{C}$ and wild type $\mathrm{T} / \mathrm{T}$ was also not significant for the Malay ethnic $(\mathrm{OR}=1.75$; $95 \% \mathrm{CI}=$ $0.61-5.03 ; \mathrm{p}=0.30)$ nor the Chinese ethnic $(\mathrm{OR}=1.50 ; 95 \%$ $\mathrm{CI}=0.54-4.13 ; \mathrm{p}=0.44)$. In addition to that, the dominant model analysis was not significant in both the Malay ethnic 
Table 5. Odds Ratios and 95\% CI of Invasive Cervical Carcinoma associated with CYP1A1 Genotypes Stratified by Cancer Type

\begin{tabular}{lccccc}
\hline $\begin{array}{l}\text { Genotype } \\
(\mathrm{n})\end{array}$ & $\begin{array}{c}\text { Controls } \\
\mathrm{n}(\%)\end{array}$ & $\begin{array}{c}\text { Cases } \\
\mathrm{n}(\%)\end{array}$ & $\mathrm{OR}^{\mathrm{b}}$ & $95 \% \mathrm{CI}$ & $\mathrm{p}$ \\
\hline $\mathrm{SCC}(37)$ & & & & & \\
$\mathrm{T} / \mathrm{T}$ & $78(40.0 \%)$ & $13(35.1 \%)$ & $1^{\mathrm{a}}$ & - & - \\
$\mathrm{T} / \mathrm{C}$ & $87(44.6 \%)$ & $16(43.2 \%)$ & 1.25 & $0.50-3.08$ & 0.63 \\
$\mathrm{C} / \mathrm{C}$ & $30(15.4 \%)$ & $8(21.6 \%)$ & 1.31 & $0.38-4.49$ & 0.67 \\
$\mathrm{ADC}(66)$ & & - & & & \\
$\mathrm{T} / \mathrm{T}$ & $78(40.0 \%)$ & $22(33.3 \%)$ & $1^{\mathrm{a}}$ & - & - \\
$\mathrm{T} / \mathrm{C}$ & $87(44.6 \%)$ & $29(43.9 \%)$ & 1.40 & $0.67-2.94$ & 0.37 \\
$\mathrm{C} / \mathrm{C}$ & $30(15.4 \%)$ & $15(22.7 \%)$ & 2.37 & $0.92-6.09$ & 0.07 \\
\hline
\end{tabular}

Reference category; ${ }^{\mathrm{b}}$ Odds ratio are based on an unconditional logistic regression model with the independent variable: types of genotype (wild type, heterozygous, homozygous variant SNP), adjusted for age

$(\mathrm{OR}=2.40 ; 95 \% \mathrm{CI}=0.90-6.39 ; \mathrm{p}=0.08)$ and the Chinese ethnic $(\mathrm{OR}=1.86 ; 95 \% \mathrm{CI}=0.72-4.84 ; \mathrm{p}=0.20)$.

Interestingly, in the Indian ethnic group, the frequency of variant $\mathrm{C} / \mathrm{C}$ genotype is observed to be less prevalent in females with cervical carcinoma (5.6\%) compared to the controls $(24.4 \%)$. Unfortunately, this difference was also not statistically significant $(95 \% \mathrm{CI}=0.01-1.63$; $\mathrm{p}=0.11)$. Dominant model analysis for the Indian ethnic group was also not significant $(\mathrm{OR}=0.84 ; 95 \% \mathrm{CI}=0.25$ 2.86; $\mathrm{p}=0.78)$.

The CYP1A1 allele frequencies of females with cervical carcinoma and controls are illustrated in Table 4. Noticeably, the frequencies of $\mathrm{C}$ allele in carcinoma cases are elevated compared to controls in the Malays (48.1\% vs $36.9 \%)$ and Chinese $(45.6 \%$ vs $35.4 \%)$. Conversely, in Indians, the $\mathrm{C}$ allele is found to be less prevalent in carcinoma cases than in controls $(33.3 \%$ vs $43.9 \%$ ). Nonetheless, cumulatively the frequency of the $\mathrm{C}$ allele is elevated in the cervical carcinoma cases $(44.8 \%)$ compared to the control population $(37.7 \%)$. However, none of these differences of the allelic associations to cervical carcinoma risk was statistically significant when analysed in the separate ethnicities or in the total population.

Additional analysis was carried out to identify association of genotype with invasive cervical carcinoma of different histopathological types. No significant association was found in either the squamous cell carcinoma or the adenocarcinoma categories as shown in Table 5. This shows that CYP1Al MspI SNP does not affect the histopathological development of cervical carcinoma.

\section{Discussion}

Tobacco smoking produces polycyclic aromatic hydrocarbons (PAH), benzo[a]pyrene and dimethylbenzoanthracene (Prokopczyk et al., 1997; Hecht, 1999; Melikian et al., 1999). CYP1Al releases the enzyme aryl hydrocarbon hydrolase $(\mathrm{AHH})$ which reacts with these hydrocarbons, releasing its reactive metabolites (Crofts et al., 1994). These metabolites include harmful carcinogens such as nicotine and cotinine (McCann et al., 1992). The reactive metabolites could bind to DNA forming DNA adducts if not properly detoxified by the GST family enzymes (Joseph et al., 2006). The accumulation of DNA adducts contributes to DNA damage, cellular transformation and elevated cancer risk (Bartsch et al., 1992; Bonassi and Au, 2002). The presence of these reactive metabolites in the cervical tissue has indicated that exposure to tobacco smoke; either first hand or second hand, may cause cellular damage of the cervix (Prokopczyk et al., 1997). This indicates that tobacco smoking may be a risk factor in cervical carcinoma.

The substitution from a thymine (T) to a cysteine (C) in the MspI restriction site of $C Y P 1 A 1$ suggests a change in the activity of $C Y P 1 A 1$ genes which could tilt the balance of bioactivation and detoxification of the reactive metabolites by GST enzymes. In fact, the presence of the $\mathrm{C}$ genotype causes $\mathrm{AHH}$ enzymatic activity to be more readily inducible (Kiyohara et al., 1996). This causes the generation of more harmful reactive metabolites from PAH in the afflicted regions which could be cell damaging especially when coupled with a subpar or compromised GST enzymatic mechanism.

In this study, the females with the $\mathrm{C} / \mathrm{C}$ genotype are associated with invasive cervical carcinoma especially when compared to the wild type T/T females. Malay females, in particular show significant increase in odds for invasive cervical carcinoma of 4.66 times when a $\mathrm{C} / \mathrm{C}$ genotype is present $(\mathrm{p}=0.03)$. Interestingly, Chinese females with the $\mathrm{C} / \mathrm{C}$ genotype was also observed to have a 3.91 increase in odds for invasive cervical carcinoma even though the association was borderline insignificant $(p=0.06)$. Similar observations were also found in other studies done in Mexico (Juarez-Cedillo et al., 2007), and Hawaii (Goodman et al., 2001) where the $\mathrm{C} / \mathrm{C}$ genotype was revealed to be a risk factor for carcinogenesis. In Mexico, women with either a $\mathrm{T} / \mathrm{C}$ or a $\mathrm{C} / \mathrm{C}$ genotype have increased risk of developing cervical cancer by 3.7 and 9.3 times respectively when compared to wild type T/T women (Juarez-Cedillo et al., 2007). In Hawaii, a multi-ethnic study shows the $\mathrm{C} / \mathrm{C}$ variant elevated the risk of cervical squamous intraepithelial lesions up to 3.4 times more than that of $\mathrm{T} / \mathrm{T}$ wild type (Goodman et al., 2001). More recently, a meta-analysis study done on 10 studies involving CYP1Al MspI SNP with cervical cancer suggests that the $\mathrm{C} / \mathrm{C}$ variant genotype increases the odds of cervical cancer by 2.06 times $(\mathrm{p}=0.02)$ compared to the wild type T/T genotype (Xia et al., 2013). In addition to that, our results also echo the findings of an earlier meta-analysis study drawing upon different groups of population showing the homozygous $\mathrm{C} / \mathrm{C}$ to have increased risk of cervical cancer by 2.66 times $(\mathrm{p}=0.02)$ more than wild type T/T (Sergentanis et al., 2012).

The Indian female population in the present study indicated that the $\mathrm{C} / \mathrm{C}$ genotype might exert a protective effect against cervical carcinoma given the OR of 0.13 $(\mathrm{p}=0.11)$. Surprisingly, $\mathrm{C} / \mathrm{C}$ genotype is observed to be a rare occurrence in Indian female cervical carcinoma cases $(5.6 \%)$. This most probably contributed to the variation seen between the Indian females and the rest of our study population. Further investigate, a dominant model analysis with $\mathrm{C}$ as the high risk allele was done and 
there was no significant associations $(\mathrm{OR}=0.84,95 \% \mathrm{CI}=$ 0.25-2.86, $\mathrm{p}=0.78$ ). Comparatively, similar studies done on the females in India found the homozygous variant $\mathrm{C} / \mathrm{C}$ genotype are significantly associated with increased OR of 4.78 for cervical cancer compared to the wild type $\mathrm{T} / \mathrm{T}$ genotype (Joseph et al., 2006). Therefore, due to the rare occurrence of $\mathrm{C} / \mathrm{C}$ genotype in Malaysian Indian study population, we advise that our output pertaining to the relation of $\mathrm{C} / \mathrm{C}$ genotype to cervical cancer in the Indian ethnicity be taken with care. To obtain a more conclusive evidence of an association between the $\mathrm{C} / \mathrm{C}$ genotype with cervical cancer, a higher number of recruitment for the Indian females would be required in a future study.

Aside from that, the $\mathrm{C} / \mathrm{C}$ genotype was moderately low in our population constituting only $17.9 \%$ of the possible genotypes outcome. Interestingly the $\mathrm{C} / \mathrm{C}$ genotype was less commonly found in all other studies involving cervical neoplasia or carcinoma of the cervix (Kim et al., 2000; Goodman et al., 2001; Joseph et al., 2006; Agorastos et al., 2007; Juarez-Cedillo et al., 2007; Nishino et al., 2008; Gutman et al., 2009; von Keyserling et al., 2011). Given this, the $\mathrm{C} / \mathrm{C}$ genotype seems to be naturally rare. Despite that, the heterozygous T/C genotype (44.5\%) was most prominently found in our study resulting in the prevalence of $\mathrm{C}$ allele to be at a moderate $40.2 \%$. Data from a meta-analysis study on lung cancer, drawing from 13 existing studies comprising of subjects from Japan, China, Korea and Thailand found that the prevalence of C allele is around $42.4 \%$ (Lee et al., 2008). More recently, a study on lung cancer in the Inner Mongolia region reported with a high level of the $\mathrm{C}$ allele $(\sim 50 \%)$ (Jiang et al., 2014) whereas a different study on esophageal cancer in Central China reported that the $\mathrm{C} / \mathrm{C}$ genotype in China to be around $237 \%$ (Yun et al., 2013). Both our data and the findings from these studies seem to be in concurrence whereby the prevalence of $\mathrm{C}$ alleles within Asian populations is generally around $35 \%$ to $50 \%$. On the other hand, the prevalence of the $\mathrm{C}$ allele within other populations was found to be largely lower. The $\mathrm{C}$ allele prevalence variation for cervical carcinogenesis for studies done in Mexicans (33.9\%) (Juarez-Cedillo et al., 2007), Indians from India (15.4\%) (Joseph et al., 2006), Germans (11.2\%) (von Keyserling et al., 2011), Israelites (12.5\%) (Gutman et al., 2009), and Greeks (12.3\%) (Agorastos et al., 2007), indicates that Asian populations have higher percentage of $\mathrm{C}$ allele prevalence compared to those oelsewhere. Since $\mathrm{C} / \mathrm{C}$ genotype contributes to higher risk of cervical cancer, the $C Y P 1 A 1 \mathrm{MspI} \mathrm{C/C}$ genotype and $\mathrm{C}$ allele could be a risk factor contributing towards cervical carcinogenesis especially within Asia.

Similar observations on the unusually low prevalence of the $\mathrm{C} / \mathrm{C}$ genotype and the $\mathrm{C}$ allele in non-Asian population were also observed in other cancer type studies. Firstly, the prevalence of the $\mathrm{C} / \mathrm{C}$ genotype in a lung cancer study on Northern India was reported to be at around 4-7\%. However, the genotype was not significantly associated with the risk of lung cancer (Shukla et al., 2013). Interestingly, the findings from North India mirrors the low $\mathrm{C} / \mathrm{C}$ genotype prevalence observed in Indian females of Malaysia. Similarly, the $\mathrm{C} / \mathrm{C}$ genotype was almost non-existent $(<1 \%)$ in a colorectal cancer susceptibility study in Saudi Arabia. The heterozygous $\mathrm{C} / \mathrm{T}$ genotype was however associated with a 3.65 fold increase of colorectal cancer risk compared to that of wild type T/T genotype (Saeed et al., 2013). Even so, it is uncertain whether the significant association or lack of in these studies was affected by the rarity of the $\mathrm{C} / \mathrm{C}$ genotype and $\mathrm{C}$ allele. These findings do indicate that the low prevalence of $\mathrm{C} / \mathrm{C}$ genotype and $\mathrm{C}$ allele is not solely observed in cervical cancer only.

Interestingly, several studies found that significant associations with carcinogenesis are more prominent in the Asian compared to the Caucasian populations potentially due to the more dominant presence of the $\mathrm{C} / \mathrm{C}$ genotype and the $\mathrm{C}$ allele in the former group. For example, a meta-analysis involving oral carcinoma shows $\mathrm{C} / \mathrm{C}$ genotype contributing a 1.94 times more significant risk in the Asian communities when compared to the wild type T/T genotype while no significant difference could be found within the Caucasian communities (Zhuo et al., 2012b). Similarly, a meta-analysis on head and neck related cancer found that Asian carriers of the variant $\mathrm{C}$ allele had a significant increased risk for cancer while no significant difference was seen within the Caucasians (Liu et al., 2013). A few other meta-analysis studies involving prostate cancer (Ding et al., 2013), and acute myeloid leukemia (Zhuo et al., 2012a) also indicate Asians, but not Caucasians, with the variant allele, to be more susceptible to carcinogenesis. Even in lung cancer, one of the most studied cancers associated with CYP1Al MspI SNP due to ease of access of tobacco carcinogen, a meta-analysis study reported that when comparing the $\mathrm{C}$ allele vs. the $\mathrm{T}$ allele, the Caucasian subgroup was only found to be marginally significant while the East Asian group was highly significant (Chen et al., 2011).

Additionally, the low prevalence of $\mathrm{C}$ alleles, and the seemingly naturally rare $\mathrm{C} / \mathrm{C}$ genotype, especially within the Caucasian communities, may be a factor that leads to the under-estimation of the significance of the CYP1A1 MspI SNP as a risk factor for cervical cancer. Certain studies with non-significant associations between the SNP and cervical cancer in Caucasian populations were observed to have low $\mathrm{C} / \mathrm{C}$ genotype and $\mathrm{C}$ allele frequencies (Agorastos et al., 2007; Gutman et al., 2009). The non-association found in these studies can therefore be attributed to the lack of $\mathrm{C} / \mathrm{C}$ genotype in the analysis resulting in an inadequate sample size for unbiased analysis and not due to the SNP not being a risk factor. This therefore indicates that the $C Y P 1 A 1 \mathrm{MspI}$ polymorphism may have more of a role in the development of cervical cancer than initially thought.

A limitation in our study is the lack of data on the smoking status of the subjects since the study was done retrospectively with DNA samples collected from archival tissues. This is critical as tobacco smoking is a known risk factor for cervical cancer (Juarez-Cedillo et al., 2007; Nishino et al., 2008). In fact, female carriers of the $\mathrm{C} / \mathrm{C}$ genotype who have a history of smoking were showed to have an increased OR of up to 19.4 fold for cervical cancer (Juarez-Cedillo et al., 2007). Despite not knowing 
the smoking status of our study subjects, the prevalence of smoking in the general Malaysian population is known to be at $23.1 \%$ with around $46.5 \%$ of male adults and $1 \%$ of women smokers (Lim et al., 2013). Of the three ethnics among Malaysians, Malay female smokers are the most prominent, followed by Chinese females while Indian females very rarely smoke (Report of the Global Adult Tobacco Survey (GATS) Malaysia 2011 p23). This could attribute to the significant association we found on the Malay females in this study. Aside from that, second-hand smoke continues to be a risk factor. At least 3.1 million non-smoking females in Malaysia are exposed to tobacco smoke either at home, at work or in public places (Report of the Global Adult Tobacco Survey (GATS) Malaysia 2011 p53). This suggests that smoking and secondary smoke continues to be a risk factor in cervical carcinogenesis among Malaysian females. Hence, identification of the patients smoking status in future studies may provide further insight towards the cervical cancer risk and $C Y P 1 A 1 \mathrm{MspI}$ polymorphism.

Furthermore, other CYP1Al related SNPs such as the Ile462 Val polymorphism should be investigated. The Ile462Val polymorphism has been previously associated with increased risk for several types of cancer such as lung, head and neck cancer and even cervical carcinoma in certain countries (Bartsch et al., 2000; Shukla et al., 2012; Roszak et al., 2014) but was also found to not alter the risk for several other cancers such as bladder and endometrial carcinoma (Wang et al., 2012; Berber et al., 2013). Since SNP prevalence differences are population based, it will be interesting to identify if a co-relationship involving the two SNPs are capable of contributing significantly towards an increase of cervical cancer risk in Malaysia.

In conclusion, the study presents $C Y P 1 A 1 \mathrm{MspI} \mathrm{C/C}$ genotype as a risk factor in the development of cervical cancer in Malaysia and especially among Malay females. Given that there is higher prevalence of $\mathrm{C}$ allele among Malaysian females in comparison with studies done on non-Asian females; ethnicity remains a major factor in determining whether the CYPIAl MspI polymorphism affects the risk of cervical cancer. The risk of developing cervical cancer is also more prominent in Malaysia given the high penetrance of second-hand smoke exposure among females. To the authors' knowledge, the present study provides the first insight towards the prevalence of CYP1A1 MspI on cervical carcinoma in a multi-ethnic Asian population and a first look at the prevalence of CYP1Al MspI SNP in a Malay population.

\section{Acknowledgements}

This study was supported by a research grant from the National Cancer Council Malaysia (MAKNA). We would like to thank: Mr Sayyidi Hamzi of Hospital Universiti Kebangsaan Malaysia (HUKM) for assisting with sample acquisition.

\section{References}

Agorastos T, Papadopoulos N, Lambropoulos AF, et al (2007). Glutathione-S-transferase M1 and T1 and cytochrome
P1A1 genetic polymorphisms and susceptibility to cervical intraepithelial neoplasia in Greek women. Eur J Cancer Prev, 16, 498-504.

Au WW, Sierra-Torres CH, Tyring SK (2003). Acquired and genetic susceptibility to cervical cancer. Mutat Res, 544, 361-4.

Autrup H (2000). Genetic polymorphisms in human xenobiotica metabolizing enzymes as susceptibility factors in toxic response. Mutat Res, 464, 65-76.

Barbisan G, Contreras A, Perez LO, Difranza L, Golijow CD (2011). The effect of TP53 codon 72 and RNASEL codon 462 polymorphisms on the development of cervical cancer in Argentine women. Cancer Genet, 204, 270-7.

Bartsch H, Nair U, Risch A, et al (2000). Genetic polymorphism of CYP genes, alone or in combination, as a risk modifier of tobacco-related cancers. Cancer Epidemiol Biomarkers Prev, 9, 3-28.

Bartsch H, Petruzzelli S, De Flora S, et al (1992). Carcinogen metabolism in human lung tissues and the effect of tobacco smoking: results from a case-control multicenter study on lung cancer patients. Environ Health Perspect, 98, 119-24.

Berber U, Yilmaz I, Yilmaz O, et al (2013). CYP1A1 (Ile462Val), CYP1B1 (Ala119Ser and Val432Leu), GSTM1 (null), and GSTT1 (null) polymorphisms and bladder cancer risk in a Turkish population. Asian Pac J Cancer Prev, 14, 3925-9.

Bonassi S, Au WW (2002). Biomarkers in molecular epidemiology studies for health risk prediction. Mutat Res, 511, 73-86.

Boyapati SM, Shu XO, Gao YT, et al (2005). Polymorphisms in CYP1Al and breast carcinoma risk in a population-based case-control study of Chinese women. Cancer, 103, 2228-35.

Chen Z, Li Z, Niu X, et al (2011). The effect of CYP1A1 polymorphisms on the risk of lung cancer: a global metaanalysis based on 71 case-control studies. Mutagenesis, 26, 437-46.

Chong PP, Asyikin N, Rusinahayati M, et al (2010). High prevalence of human papillomavirus DNA detected in cervical swabs from women in southern Selangor, Malaysia. Asian Pac J Cancer Prev, 11, 1645-51.

Crofts F, Taioli E, Trachman J, et al (1994). Functional significance of different human CYP1A1 genotypes. Carcinogenesis, 15, 2961-3.

Ding G, Xu W, Liu H, et al (2013). CYP1A1 MspI polymorphism is associated with prostate cancer susceptibility: evidence from a meta-analysis. Mol Biol Rep, 40, 3483-91.

Goodman MT, McDuffie K, Hernandez B, et al (2001). CYP1A1, GSTM1, and GSTT1 polymorphisms and the risk of cervical squamous intraepithelial lesions in a multiethnic population. Gynecol Oncol, 81, 263-9.

Gutman G, Morad T, Peleg B, et al (2009). CYP1A1 and CYP2D6 gene polymorphisms in Israeli Jewish women with cervical cancer. Int J Gynecol Cancer, 19, 1300-2.

Hamzi Abdul Raub S, Isa NM, Zailani HA, et al (2014). Distribution of HPV genotypes in cervical cancer in multiethnic Malaysia. Asian Pac J Cancer Prev, 15, 651-6.

Hecht SS (1999). DNA adduct formation from tobacco-specific N-nitrosamines. Mutat Res, 424, 127-42.

Hoory T, Monie A, Gravitt P, Wu TC (2008). Molecular epidemiology of human papillomavirus. J Formos Med Assoc, 107, 198-217.

Islam MS, Ahmed MU, Sayeed MS, et al (2013). Lung cancer risk in relation to nicotinic acetylcholine receptor, CYP2A6 and CYPlAl genotypes in the Bangladeshi population. Clin Chim Acta, 416, 11-9.

Jiang XY, Chang FH, Bai TY, Lv XL, Wang MJ (2014). Susceptibility of lung cancer with polymorphisms of CYP1A1, GSTM1, GSTM3, GSTT1 and GSTP1 genotypes 
Yee Hock Tan et al in the population of Inner Mongolia region. Asian Pac J Cancer Prev, 15, 5207-14.

Joseph T, Chacko P, Wesley R, et al (2006). Germline genetic polymorphisms of CYP1A1, GSTM1 and GSTT1 genes in Indian cervical cancer: associations with tumor progression, age and human papillomavirus infection. Gynecol Oncol, 101, 411-7.

Juarez-Cedillo T, Vallejo M, Fragoso JM, et al (2007). The risk of developing cervical cancer in Mexican women is associated to CYP1A1 MspI polymorphism. Eur J Cancer, 43, 1590-5.

Kim JW, Lee CG, Park YG, et al (2000). Combined analysis of germline polymorphisms of p53, GSTM1, GSTT1, CYP1A1, and CYP2E1: relation to the incidence rate of cervical carcinoma. Cancer, 88, 2082-91.

Kiyohara C, Hirohata T, Inutsuka S (1996). The relationship between aryl hydrocarbon hydroxylase and polymorphisms of the CYP1A1 gene. Jpn J Cancer Res, 87, 18-24.

Lee KM, Kang D, Clapper ML, et al (2008). CYP1A1, GSTM1, and GSTT1 polymorphisms, smoking, and lung cancer risk in a pooled analysis among Asian populations. Cancer Epidemiol Biomarkers Prev, 17, 1120-6.

Lim HK, Ghazali SM, Kee CC, et al (2013). Epidemiology of smoking among Malaysian adult males: prevalence and associated factors. BMC Public Health, 13, 8.

Liu L, Wu G, Xue F, et al (2013). Functional CYP1Al genetic variants, alone and in combination with smoking, contribute to development of head and neck cancers. Eur J Cancer, 49, 2143-51.

McCann MF, Irwin DE, Walton LA, et al (1992). Nicotine and cotinine in the cervical mucus of smokers, passive smokers, and nonsmokers. Cancer Epidemiol Biomarkers Prev, 1, 125-9.

Melikian AA, Sun P, Prokopczyk B, et al (1999). Identification of benzo[a]pyrene metabolites in cervical mucus and DNA adducts in cervical tissues in humans by gas chromatographymass spectrometry. Cancer Lett, 146, 127-34.

Nishino K, Sekine M, Kodama S, et al (2008). Cigarette smoking and glutathione $\mathrm{S}$-transferase M1 polymorphism associated with risk for uterine cervical cancer. J Obstet Gynaecol Res, 34, 994-1001.

Parkin DM, Bray F, Ferlay J, Pisani P (2005). Global cancer statistics, 2002. CA Cancer J Clin, 55, 74-108.

Prokopczyk B, Cox JE, Hoffmann D, Waggoner SE (1997). Identification of tobacco-specific carcinogen in the cervical mucus of smokers and nonsmokers. J Natl Cancer Inst, 89, 868-73.

Remmink AJ, Walboomers JM, Helmerhorst TJ, et al (1995). The presence of persistent high-risk HPV genotypes in dysplastic cervical lesions is associated with progressive disease: natural history up to 36 months. Int J Cancer, 61, 306-11.

Report of the Global Adult Tobacco Survey (GATS) Malaysia 2011 (2012). Institute for Public Health, National Institute of Health, Ministry of Health, Malaysia. 23,53

Roszak A, Lianeri M, Sowinska A, Jagodzinski PP (2014). CYP1A1 Ile462Val polymorphism as a risk factor in cervical cancer development in the Polish population. Mol Diagn Ther, 18, 445-50.

Saeed HM, Alanazi MS, Nounou HA, et al (2013). Cytochrome P450 1A1, 2E1 and GSTM1 gene polymorphisms and susceptibility to colorectal cancer in the Saudi population. Asian Pac J Cancer Prev, 14, 3761-8.

Schiffman M, Castle PE, Jeronimo J, Rodriguez AC, Wacholder S (2007). Human papillomavirus and cervical cancer. Lancet, 370, 890-907.

Sergentanis TN, Economopoulos KP, Choussein S, Vlahos NF (2012). Cytochrome P450 1A1 (CYP1A1) gene polymorphisms and cervical cancer risk: a meta-analysis.
Mol Biol Rep, 39, 6647-54.

Sharifah NA, Seeni A, Nurismah MI, et al (2009). Prevalence of human papillomavirus in abnormal cervical smears in Malaysian patients. Asian Pac J Cancer Prev, 10, 303-6.

Shukla D, Dinesh Kale A, Hallikerimath S, Vivekanandhan S, Venkatakanthaiah Y (2012). Genetic polymorphism of drug metabolizing enzymes (GSTM1 and CYP1A1) as risk factors for oral premalignant lesions and oral cancer. Biomed Pap Med Fac Univ Palacky Olomouc Czech Repub, 156, 253-9.

Shukla RK, Tilak AR, Kumar C, et al (2013). Associations of CYP1A1, GSTM1 and GSTT1 polymorphisms with lung cancer susceptibility in a Northern Indian population. Asian Pac J Cancer Prev, 14, 3345-9.

Sivaraman L, Leatham MP, Yee J, et al (1994). CYP1A1 genetic polymorphisms and in situ colorectal cancer. Cancer Res, $\mathbf{5 4 , 3 6 9 2 - 5 . ~}$

Smith G, Stubbins MJ, Harries LW, Wolf CR (1998). Molecular genetics of the human cytochrome P450 monooxygenase superfamily. Xenobiotica, 28, 1129-65.

Smith JS, Lindsay L, Hoots B, et al (2007). Human papillomavirus type distribution in invasive cervical cancer and high-grade cervical lesions: a meta-analysis update. Int J Cancer, 121, 621-32.

Spurr NK, Gough AC, Stevenson K, Wolf CR (1987). Msp-1 polymorphism detected with a cDNA probe for the P-450 I family on chromosome 15. Nucleic Acids Res, 15, 5901.

Sreelekha TT, Ramadas K, Pandey M, et al (2001). Genetic polymorphism of CYP1A1, GSTM1 and GSTT1 genes in Indian oral cancer. Oral Oncol, 37, 593-8.

Tanimoto K, Hayashi S, Yoshiga K, Ichikawa T (1999). Polymorphisms of the CYP1Al and GSTM1 gene involved in oral squamous cell carcinoma in association with a cigarette dose. Oral Oncol, 35, 191-6.

von Keyserling H, Bergmann T, Schuetz M, et al (2011). Analysis of 4 single-nucleotide polymorphisms in relation to cervical dysplasia and cancer development using a high-throughput ligation-detection reaction procedure. Int J Gynecol Cancer, 21, 1664-71.

Wang XW, Zhong TY, Xiong YH, Lin HB, Liu QY (2012). Lack of association between the CYP1A1 Ile462Val polymorphism and endometrial cancer risk: a meta-analysis. Asian Pac J Cancer Prev, 13, 3717-21.

Xia L, Gao J, Liu Y, Wu K (2013). Significant association between CYP1A1 T3801C polymorphism and cervical neoplasia risk: a systematic review and meta-analysis. Tumour Biol, 34, 223-30.

Yun YX, Wang YP, Wang P, et al (2013). CYP1A1 genetic polymorphisms and risk for esophageal cancer: a casecontrol study in central China. Asian Pac J Cancer Prev, 14, 6507-12.

Zainal Ariffin O, Nor Saleha IT (2011). National cancer registry report, Malaysia cancer statistics-data and figure 2007, National Cancer Registry, Ministry of Health, Malaysia. 42-3

Zhuo W, Zhang L, Wang Y, Zhu B, Chen Z (2012a). CYP1A1 MspI polymorphism and acute myeloid leukemia risk: meta-analyses based on 5018 subjects. J Exp Clin Cancer Res, 31, 62 .

Zhuo X, Zhao H, Chang A, et al (2012b). Quantitative assessment of CYP1A $1 * 2 \mathrm{~A}$ variations with oral carcinoma susceptibility: evidence from 1,438 cases and 2,086 controls. Cancer Invest, 30, 552-9. 